\title{
Stopping long-acting beta2-agonists (LABA) for children with asthma well controlled on LABA and inhaled corticosteroids (Review)
}

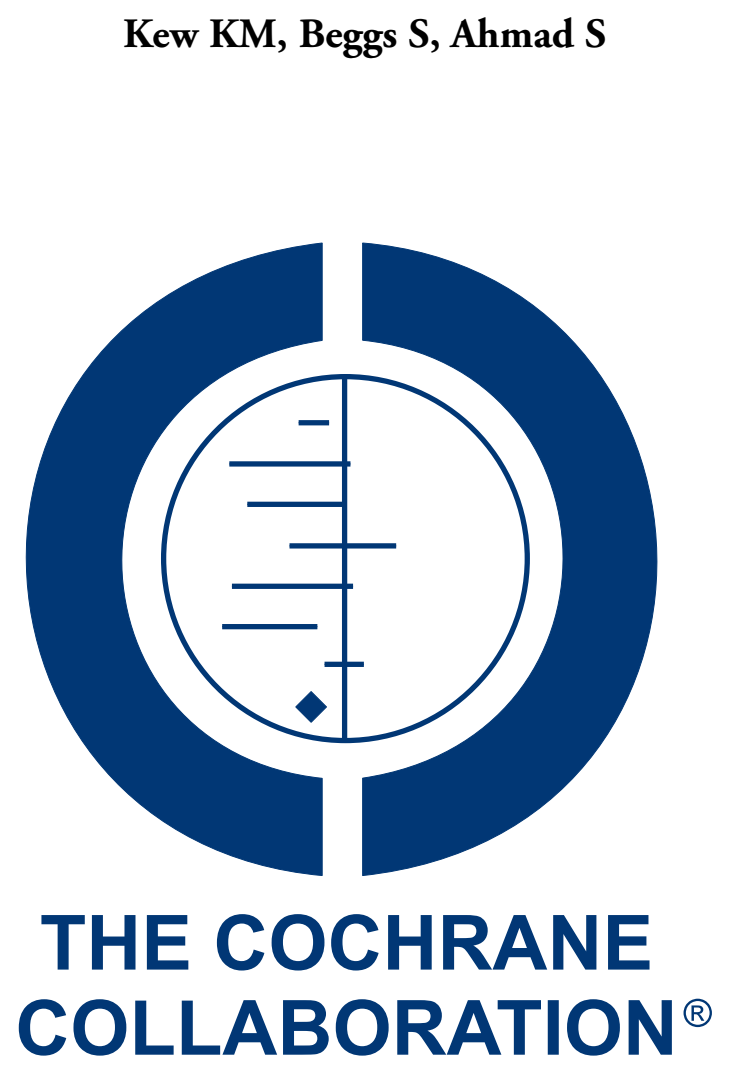

This is a reprint of a Cochrane review, prepared and maintained by The Cochrane Collaboration and published in The Cochrane Library 2015, Issue 5

http://www.thecochranelibrary.com

\section{WILEY}

Stopping long-acting beta2-agonists (LABA) for children with asthma well controlled on LABA and inhaled corticosteroids (Review) Copyright $\odot 2015$ The Cochrane Collaboration. Published by John Wiley \& Sons, Ltd. 
TABLE OF CONTENTS

HEADER . . . . . . . . . . . . . . . . . . . . . . . . . . . . . . . . . . . . 1

ABSTRACT . . . . . . . . . . . . . . . . . . . . . . . . . . . . . . . . . . . . . . . . . . . . . . .

PLAIN LANGUAGE SUMMARY . . . . . . . . . . . . . . . . . . . . . . . . . . . . . . . . . . . .

SUMMARY OF FINDINGS FOR THE MAIN COMPARISON $\quad$. . . . . . . . . . . . . . . . . . . . . . . . . . . 4

BACKGROUND . . . . . . . . . . . . . . . . . . . . . . . . . . . . . . . . . . . . . . . . 4

OBJECTIVES . . . . . . . . . . . . . . . . . . . . . . . . . . . . . . . . . . . . . . . . . . . .

METHODS . . . . . . . . . . . . . . . . . . . . . . . . . . . . . . . . . . . . . 6

Figure 1. . . . . . . . . . . . . . . . . . . . . . . . . . . . . . . . . . . . . . 8

RESULTS . . . . . . . . . . . . . . . . . . . . . . . . . . . . . . . . . . . . . . . 10

DISCUSSION . . . . . . . . . . . . . . . . . . . . . . . . . . . . . . . . . . . . . . . . . . . .

AUTHORS' CONCLUSIONS . . . . . . . . . . . . . . . . . . . . . . . . . . . . . . . . . . . 12

ACKNOWLEDGEMENTS . . . . . . . . . . . . . . . . . . . . . . . . . . . . . . . . . . 12

REFERENCES . . . . . . . . . . . . . . . . . . . . . . . . . . . . . . . . . . . . . . . . 13

CHARACTERISTICS OF STUDIES . . . . . . . . . . . . . . . . . . . . . . . . . . . . . . . . . . . . . .

DATA AND ANALYSES . . . . . . . . . . . . . . . . . . . . . . . . . . . . . . . . . . . 21

APPENDICES . . . . . . . . . . . . . . . . . . . . . . . . . . . . . . . . . . . . . . 21

CONTRIBUTIONS OF AUTHORS . . . . . . . . . . . . . . . . . . . . . . . . . . . . . . . . . . . . . . . . . .

DECLARATIONS OF INTEREST . . . . . . . . . . . . . . . . . . . . . . . . . . . . . . . . . . . . . . . . .

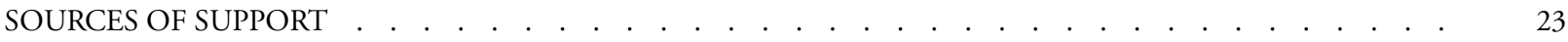

DIFFERENCES BETWEEN PROTOCOL AND REVIEW . . . . . . . . . . . . . . . . . . . . . . . . . . . . .

Stopping long-acting beta2-agonists (LABA) for children with asthma well controlled on LABA and inhaled corticosteroids (Review)

Copyright $\odot 2015$ The Cochrane Collaboration. Published by John Wiley \& Sons, Ltd. 


\title{
[Intervention Review]
}

\section{Stopping long-acting beta2-agonists (LABA) for children with asthma well controlled on LABA and inhaled corticosteroids}

\author{
Kayleigh M Kew ${ }^{1}$, Sean Beggs ${ }^{2,3}$, Shaleen Ahmad ${ }^{1}$ \\ ${ }^{1}$ Population Health Research Institute, St George's, University of London, London, UK. ${ }^{2}$ Department of Paediatrics, Royal Hobart \\ Hospital, Hobart, Australia. ${ }^{3}$ School of Medicine, University of Tasmania, Hobart, Australia \\ Contact address: Kayleigh M Kew, Population Health Research Institute, St George's, University of London, Cranmer Terrace, London, \\ SW170RE, UK. kkew@sgul.ac.uk.
}

Editorial group: Cochrane Airways Group.

Publication status and date: New, published in Issue 5, 2015.

Review content assessed as up-to-date: 8 April 2015.

Citation: Kew KM, Beggs S, Ahmad S. Stopping long-acting beta2-agonists (LABA) for children with asthma well controlled on LABA and inhaled corticosteroids. Cochrane Database of Systematic Reviews 2015, Issue 5. Art. No.: CD011316. DOI: 10.1002/14651858.CD011316.pub2.

Copyright (C) 2015 The Cochrane Collaboration. Published by John Wiley \& Sons, Ltd.

\begin{abstract}
A B S T R A C T
Background

Asthma is the most common chronic medical condition among children and is one of the most common causes of hospitalisation and medical visits. Poorly controlled asthma often leads to preventable exacerbations that require additional medications, hospital stays, or treatment in the emergency department.

Long-acting beta 2 -agonists (LABA) are the preferred add-on treatment for children with asthma whose symptoms are not well controlled on inhaled corticosteroids (ICS). The US Food and Drug Administration has issued a 'black box' warning for LABA in asthma, and now recommends that they be used "for the shortest duration of time required to achieve control of asthma symptoms and discontinued, if possible, once asthma control is achieved".
\end{abstract}

Objectives

To compare the effect on asthma control and adverse effects of stepping down to inhaled corticosteroids (ICS)-only therapy versus continuing ICS plus LABA in children whose asthma is well controlled on combined ICS and LABA therapy.

\section{Search methods}

We searched the Cochrane Airways Group Specialised Register, and also searched www.ClinicalTrials.gov, www.who.int/ictrp/en/, reference lists of primary studies and existing reviews, and manufacturers' trial registries (GlaxoSmithKline and AstraZeneca). We searched all databases from their inception to the present, and imposed no restriction on language of publication. The most recent search was done in April 2015.

\section{Selection criteria}

We looked for parallel randomised controlled trials of at least eight weeks' duration, available as published full text, abstract only, or unpublished data. We excluded studies including participants with other chronic respiratory comorbidities (for example bronchiectasis).

We looked for studies in which children (18 years or younger) whose asthma was well controlled on any dose of ICS and LABA combination therapy were randomised to: a) step-down therapy to ICS alone or b) continued use of ICS and LABA.

Stopping long-acting beta2-agonists (LABA) for children with asthma well controlled on LABA and inhaled corticosteroids (Review)

Copyright @ 2015 The Cochrane Collaboration. Published by John Wiley \& Sons, Ltd. 
We included any dose of LABA (formoterol, salmeterol, vilanterol) and any dose of ICS (beclomethasone, budesonide, ciclesonide, mometasone, flunisolide, fluticasone propionate, fluticasone furoate, triamcinolone) delivered in a combination inhaler or in separate inhalers.

\section{Data collection and analysis}

Two review authors independently screened all records identified in the searches. We used a data extraction tool in Microsoft Excel to manage searches and document reasons for inclusion and exclusion, and to extract descriptive and numerical data from trials meeting the inclusion criteria.

The prespecified primary outcomes were exacerbations requiring oral steroids, asthma control, and all-cause serious adverse events.

\section{Main results}

Despite conducting extensive searches of electronic databases, trial registries and manufacturers' websites we identified no trials matching the inclusion criteria.

After removing duplicates, we screened 1031 abstracts, and assessed 43 full-text articles for inclusion. We identified several adult studies, which will be summarised in a separate review (Ahmad 2014). The most common reasons for exclusion after viewing full texts were 'wrong comparison' ( $\mathrm{n}=22$ ) and 'adult population' $(\mathrm{n}=18)$.

Some adult studies recruited adolescents from age 15, but none reported data separately for those under 18.

\section{Authors' conclusions}

There is currently no evidence from randomised trials to inform the discontinuation of LABAs in children once asthma control is achieved with ICS plus LABA. It is disappointing that such an important issue has not been studied, and a randomised double-blind trial recruiting children who are controlled on ICS plus LABA is warranted. The study should be large enough to assess children of different ages, and to measure the important safety and efficacy outcomes suggested in this review over at least six months.

The only randomised evidence for stopping LABA has been conducted in adults; it will be summarised in a separate review.

\section{PLAIN LANGUAGE SUMMARY}

\section{Stopping long-acting beta 2 -agonists for children well controlled on combination therapy}

\section{Background}

Asthma is the most common long-term medical condition in children. Poorly controlled asthma often leads to flare-ups that require extra treatment, hospital stays, or treatment in the emergency department.

Long-acting beta 2 -agonists (LABA) are an inhaled treatment that can be added to inhaled corticosteroids (ICS) for children with asthma whose symptoms are not well controlled on ICS alone. The US Food and Drug Administration issued a warning for the use of LABA in asthma after serious safety concerns emerged, and now recommends that they be used for the shortest time possible, and stopped when the child's asthma improves.

\section{Review question}

We looked for studies comparing a group of children who stopped taking their LABA with a group who continued taking ICS plus LABA. We were mainly interested in whether there is an effect on asthma control and side effects of stopping LABA.

Studies had to be at least eight weeks' long and include children whose asthma was well controlled on any dose of ICS plus LABA.

Two review authors independently screened all records found in the searches, which were done in April 2015.

\section{Results}

We found no studies matching the criteria above.

We screened 1031 records and read the full text of 43 articles we thought looked relevant, but could include none. We found several adult studies, which will be summarised in a separate review (Ahmad 2014).

Some adult studies included adolescents from age 15, but none reported data separately for those under 18.

Stopping long-acting beta2-agonists (LABA) for children with asthma well controlled on LABA and inhaled corticosteroids (Review) 


\section{Conclusion}

There is currently no evidence from randomised studies looking at stopping LABA in children whose asthma is well controlled on ICS plus LABA, which is disappointing given the importance of the question.

We will summarise studies in adults in a separate review (Ahmad 2014). 
SUMMARY OF FINDINGS FOR THE MAIN COMPARISON [Explanation]

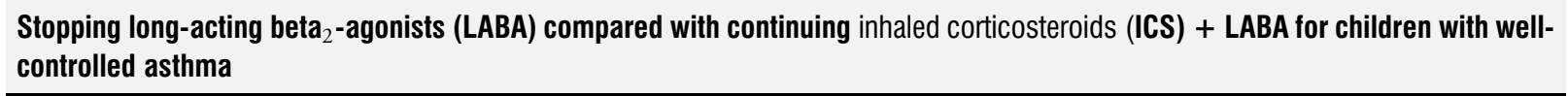

Patient or population: children (aged 18 years or younger) whose asthma is well controlled on combination ICS + LABA

Settings: outpatient

Intervention: stopping LABA

Comparison: continuing ICS + LABA

\begin{tabular}{|c|c|c|}
\hline Outcomes & $\begin{array}{l}\text { No of Participants } \\
\text { (studies) }\end{array}$ & Comments \\
\hline $\begin{array}{l}\text { Exacerbations requiring systemic corticos- } \\
\text { teroids }\end{array}$ & $0(0)$ & No studies met the inclusion criteria for the review \\
\hline Asthma control (validated scales) & $0(0)$ & \\
\hline Serious adverse events (all cause) & $0(0)$ & \\
\hline Quality of life (validated scales) & $0(0)$ & \\
\hline $\begin{array}{l}\text { Exacerbations requiring hospitalisation or } \\
\text { emergency department visit }\end{array}$ & $0(0)$ & \\
\hline Adverse events (all cause) & $0(0)$ & \\
\hline Withdrawals & $0(0)$ & \\
\hline
\end{tabular}

\section{B A C K G RO U N D}

\section{Description of the condition}

Asthma is a long-term respiratory condition that causes difficulty breathing due to narrowing of the airways, thickening of the airway walls, and mucus buildup. Symptoms include wheezing, shortness of breath, chest tightness, and cough that vary over time in their occurrence, frequency, and intensity (GINA 2014).

Asthma is the most common chronic medical condition among children and is one of the most common causes of hospitalisation and medical visits in children (PHAC 2007). The condition frequently goes undiagnosed and untreated, and the direct treatment costs together with indirect costs associated with lost productivity are among the highest for non-communicable diseases (Global Asthma Report 2011). Recent estimates suggest that 235 million people are affected worldwide, and this figure continues to rise in low- and middle-income countries (Global Asthma Report 2011). Prevalence has been linked to various factors including air pollution, tobacco legislation, diet, and prevalence of other atopic diseases (Anderson 2005).

The two main aims of asthma treatment are daily control of symptoms and prevention of asthma attacks, or 'exacerbations'. These can usually be achieved in progressive treatment 'steps', depending on the severity and frequency of symptoms (Australian Asthma Handbook 2014; BTS/SIGN 2012; GINA 2014; NAEPP 2007). Many children with asthma have intermittent symptoms that can be managed with as-needed medications (for example salbutamol), but some require regular treatment with inhaled corticosteroids (ICS) alone or in combination with other longer-acting bronchodilator medications (GINA 2009; GINA 2014). Poorly controlled asthma is a significant burden on health services, often leading to preventable exacerbations that require additional medications, hospital stays, or treatment in the emergency department

Stopping long-acting beta2-agonists (LABA) for children with asthma well controlled on LABA and inhaled corticosteroids (Review) 
to bring symptoms back under control (BTS 2011). A recent UK inquiry into asthma deaths in 2012 and 2013 found that there was an association between mortality and avoidable factors such as poor compliance to regular medications (48\%) and overuse of short-acting beta 2 -agonists (39\%) (NRAD 2014).

\section{Description of the intervention}

The initial starting therapy for asthma is as-needed reliever (bronchodilator) inhalers such as salbutamol or terbutaline; this is commonly referred to as step 1 therapy. ICS is the preventer therapy primarily recommended for people with persistent asthma who do not gain sufficient control from as-needed reliever medications; this is step 2 therapy (Australian Asthma Handbook 2014; BTS/SIGN 2012; GINA 2014). Regular use of ICS has been shown to improve lung function and reduce the need for reliever medications (Adams 2005; Adams 2009); however, a subset of people have asthma that remains uncontrolled on ICS alone. In addition, the dose-response relationship of regular ICS is not well established in children (Zhang 2011).

Beyond step 2, national treatment guidelines recommend long-

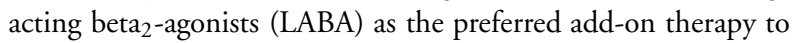
ICS when a person does not achieve asthma control on ICS and short-acting reliever medication (Australian Asthma Handbook 2014; BTS/SIGN 2012; GINA 2014). Evidence from randomised trials has shown that LABA add-on to ICS has significant benefits for lung function, reliever use, and frequency of exacerbations for adults whose asthma is not well controlled and that this is preferable to increasing the ICS dose in adults (Ducharme 2010). However, for children, the benefits of adding a LABA are less clear ( Ducharme 2008; Lemanske 2011); increasing the ICS dose may be more practical than adding a new medication. A Cochrane review showed that the addition of LABA to ICS in children was not associated with a significant reduction in the rate of exacerbations requiring systemic steroids, but was superior for improving lung function compared to the same dose of ICS alone (Ni Chroinin 2009).

In terms of safety, large adult surveillance studies and meta-analyses of randomised trials have shown a link between LABA and increased asthma morbidity and mortality (Cates 2014; Nelson 2006; Salpeter 2006). Evidence in children is less clear due to a lack of similarly sized surveillance studies (Cates 2012b), but it has been suggested that the risk of adverse asthma events may be greater for children, especially those aged 4 to 11 (McMahon 2011). It is not yet known whether either of the two most widely used LABAs, formoterol and salmeterol, is safer than the other for children with asthma (Cates 2012b).

In 2010, the US Food and Drug Administration (FDA) issued a 'black box' warning for LABA, the strictest warning put on the labelling of prescription drugs when there is reasonable evidence of an association with a serious hazard. The warning was issued after the FDA's analyses of clinical trials showed an "increased risk of severe worsening of asthma symptoms, leading to hospitalisation in both children and adults and death in some patients with asthma” (FDA 2010). Alongside the existing safety recommendations, the FDA has since required that manufacturers' labels state that LABA should only be used "for the shortest duration of time required to achieve control of asthma symptoms and discontinued, if possible, once asthma control is achieved". The FDA has since mandated large-scale clinical trials to assess the risks associated with LABA, which are currently under way, including a trial in children (NCT01462344).

Other reviews including meta-analysis of non-randomised trials have suggested that the risks of LABA may have been overstated and that the benefits outweigh the risks for the majority of patients, perhaps because several older studies have allowed the use of LABA as monotherapy (Hernández 2014; Oppenheimer 2008). This field of thought suggests that a blanket warning for LABA may actually be harmful to patients who are well controlled on ICS plus LABA, and that research should focus on identifying the subset of patients who might be at risk.

\section{How the intervention might work}

ICS reduce mucus buildup and exacerbations by reducing inflammation in the airways (Barnes 1993); they can be taken once (fluticasone furoate) or twice (beclomethasone, budesonide, fluticasone propionate) daily. LABA act as a bronchodilator by relaxing bronchial wall smooth muscle and can also be taken once (vilanterol) or twice (formoterol, salmeterol) daily (Nelson 1995).

The use of LABA and ICS in combination can allow for lower steroid doses to be used, which is important to minimise side effects of steroid use in childhood such as growth suppression (Pruteanu 2014; Zhang 2014). However, beta2-agonists carry their own risks, and there has been much debate regarding the possible causal links between their use and increased mortality and morbidity (Cates 2012a; Tattersfield 2006). Theories of beta 2 -agonist-related death and adverse events include direct toxicity of the drugs themselves, in particular their cardiac effects(Brown 1983); reduced response to beta ${ }_{2}$-agonists over time causing a gradual worsening of disease (Lipworth 1997); and delay in receiving medical help due to the masking of underlying inflammation, known as the delay hypothesis (Bijl-Hofland 2001). It has also been suggested that the delay hypothesis is linked to a reduction in compliance with appropriate ICS treatment (Johnston 2009), although this is less of an issue since the introduction of combination inhalers. Confounding by severity, in the sense that people with more severe disease are likely to be taking LABA, has now been dismissed, since it cannot explain the overall increase in mortality in the 1960s and 1970s and evidence from large case-control studies of beta 2 -agonists (Crane 1989). 


\section{Why it is important to do this review}

Despite the established evidence of safety concerns associated with the use of LABA in uncontrolled asthma for adults, evidence for the safety and efficacy of LABA is less well established for children. Furthermore, there is limited evidence to support or guide LABA discontinuation in adults or children once asthma control is achieved with ICS plus LABA. The optimal duration of ICS plus LABA therapy, or at what point to step down treatment once good symptom control has been achieved, is not yet known. While it has been shown that the detrimental effects of regular LABA use are less marked when used in combination with ICS (Cates 2012b; Ernst 2006), and particularly with a combination inhaler (FDA 2010), evidence from a Cochrane review was not able to conclude whether the risk of adverse events remains higher than with ICS alone (Ducharme 2008). Reviews have suggested that the effects of adding LABA to ICS in children are different when compared to adults (Ducharme 2010)

There are a variety of possible reasons why the risk-benefit ratio of LABA may be different in adults compared with children and adolescents, including age-related changes in pathophysiology and phenotypes (Bush 2009), as well as being numerous phenotypes within the paediatric age range (Spycher 2010). There are also challenges associated with diagnosis, monitoring tests, and taking medications that are specific to younger people, which warrant addressing the two populations separately.

\section{O B JECT IVES}

To compare the effect on asthma control and adverse effects of stepping down to ICS-only therapy versus continuing ICS plus LABA in children whose asthma is well controlled on combined ICS plus LABA therapy.

\section{METHODS}

\section{Criteria for considering studies for this review}

\section{Types of studies}

We were interested in parallel randomised controlled trials (RCTs) of at least eight weeks' duration. We included studies reported as full text, those published as abstract only, and unpublished data. We did not include cross-over trials, as they were not suitable for the assessment of long-term outcomes.

\section{Types of participants}

We looked for studies of children aged 17 or younger whose asthma was well controlled with maintenance LABA and ICS. We prespecified that participants' asthma control should be classified according to prespecified criteria, for example below a score of 1.5 on the Asthma Control Questionnaire or the criteria for control described in GINA 2014 guidelines (that is daytime symptoms twice or less per week, need for rescue inhaler twice or less per week, no nocturnal symptoms, and no limitation to daily activities).

If studies included both children and adults, we would only have included the subset of relevant participants if the study authors had been able to provide disaggregated data for participants who fit the inclusion criteria. We excluded studies including participants with other chronic respiratory comorbidities (for example bronchiectasis).

\section{Types of interventions}

We looked for studies in which children whose asthma was well controlled on any dose of ICS plus LABA combination therapy were randomised to step-down therapy to ICS alone (continued at the same dose received prior to randomisation) versus continued use of ICS and LABA (any preparation at the same dose received prior to randomisation).

We included any dose of LABA (formoterol, salmeterol, vilanterol) and any dose of ICS (beclomethasone, budesonide, ciclesonide, mometasone, flunisolide, fluticasone propionate, fluticasone furoate, triamcinolone) delivered in a combination inhaler or in separate inhalers. We included studies that gave a different ICS in the intervention group, provided it was at the same beclomethasone dipropionate equivalent dose as the ICS received prior to stopping LABA, as this may reflect what happens in practice (for example replacing salmeterol/fluticasone with beclomethasone).

One possible treatment strategy in asthma is to reduce the dose of both LABA and ICS concurrently once asthma control has been achieved (rather than stopping LABA); however, we did not include studies addressing the effect of this intervention, as this is a separate clinical question.

We included trials that allowed short-acting reliever medications, provided they were not part of the randomised treatment.

\section{Types of outcome measures}

\section{Primary outcomes}

1. Exacerbations requiring systemic corticosteroids

2. Asthma control* (measured on a validated scale, e.g. Asthma Control Questionnaire)

3. Serious adverse events (all cause)

Stopping long-acting beta2-agonists (LABA) for children with asthma well controlled on LABA and inhaled corticosteroids (Review) 
We chose the primary outcomes to represent an important measure of resource use, a patient-important outcome, and a measure of safety.

\section{Secondary outcomes}

1. Quality of life* (measured on a validated scale, e.g. Asthma Quality of Life Questionnaire)

2. Exacerbations requiring hospitalisation or emergency department (ED) visit

3. Adverse events (all cause)

4. Withdrawals

Reporting one or more of the outcomes listed here in the trial was not an inclusion criterion for the review.

*If more than one scale measuring the same construct was reported within a study, or if different scales were used across studies, we planned to analyse them using standardised mean difference.

If trials reported exacerbations as a composite that was not listed (for example hospitalisation or ED visit or systemic corticosteroids), we planned to analyse these separately.

If we identified any economic evaluations based on RCTs that make the comparison of interest in the main search, we summarised them narratively to supplement the main systematic review of effects.

\section{Search methods for identification of studies}

\section{Electronic searches}

We identified trials from the Cochrane Airways Group's Specialised Register (CAGR), which is maintained by the Trials Search Co-ordinator for the Group. The CAGR contains trial reports identified through systematic searches of bibliographic databases including the Cochrane Central Register of Controlled Trials (CENTRAL), MEDLINE, EMBASE, CINAHL, AMED, and PsycINFO, and handsearching of respiratory journals and meeting abstracts (see Appendix 1 for further details). We searched all records in the CAGR using the search strategy in Appendix 2.
We also

conducted

searches of ClinicalTrials.gov (www.ClinicalTrials.gov), the World Health Organization (WHO) trials portal (www.who.int/ictrp/ en/), and manufacturers' trial registries (GlaxoSmithKline and AstraZeneca). We searched all databases from their inception to April 2015, and imposed no restriction on language of publication.

\section{Searching other resources}

We checked reference lists of any relevant primary studies and review articles for additional references. We searched relevant manufacturers' websites for trial information.

If included studies were found, we searched for errata or retractions published in full text on PubMed (www.ncbi.nlm.nih.gov/ pubmed).

\section{Data collection and analysis}

The following sections detail the methods we planned to use had we identified any included studies. With the exception of 'Selection of studies', we could not carry out any of the planned methods of data extraction, 'Risk of bias' assessment, and analysis for this version, but have left them intact for updates of the review in case future trials are identified.

\section{Selection of studies}

One review author $(\mathrm{KK})$ and the author of the equivalent adult review (SA) independently screened titles and abstracts identified by the searches for inclusion in the review. We coded results as 'retrieve' (eligible or potentially eligible/unclear) or 'do not retrieve'. We obtained the full-text study reports or publications, and two review authors (KK and SA or SB) independently screened the fulltexts to identify studies for inclusion. We identified and recorded reasons for exclusion of the ineligible studies, resolving any disagreements through discussion or by consulting a third person (SA or SB). We identified and excluded duplicates and collated multiple reports of the same study so that each study, rather than each report, was the unit of interest in the review. We recorded the selection process in sufficient detail to complete a PRISMA flow diagram (Figure 1) and 'Characteristics of excluded studies' table. 
Figure I. Results of the search and study selection process

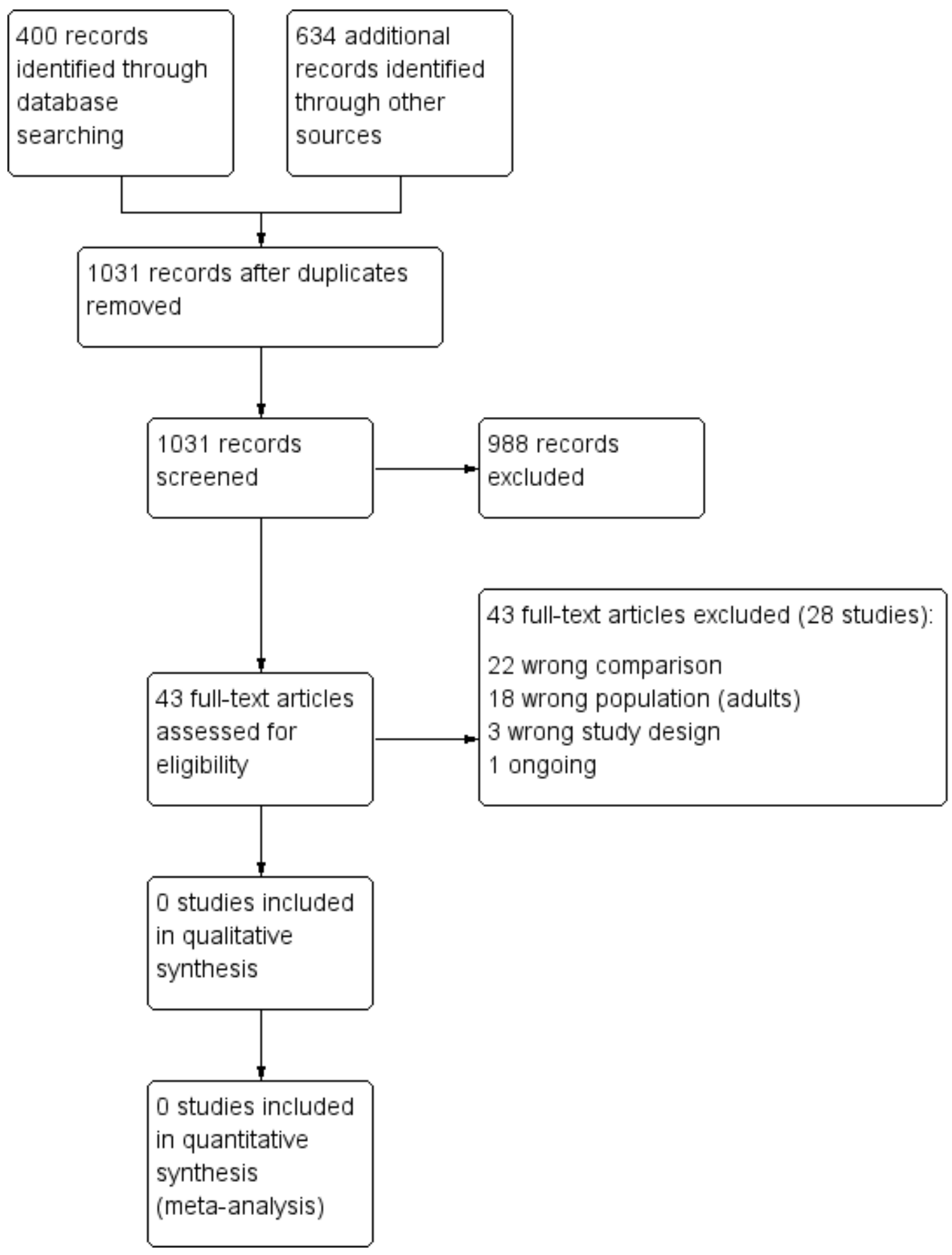




\section{Data extraction and management}

If we can include studies in future updates, we will use a Microsoft Excel data collection form for study characteristics and outcome data that has been piloted on previous reviews. One review author (KK) will extract the following study characteristics from included studies.

1. Methods: study design, total duration of study, details of any 'run in' period, number of study centres and location, study setting, withdrawals, and date of study

2. Participants: $\mathrm{N}$, mean age, age range, gender, severity of condition, diagnostic criteria, baseline lung function, smoking history, inclusion criteria, and exclusion criteria

3. Interventions: intervention, comparison, concomitant medications, and excluded medications

4. Outcomes: primary and secondary outcomes specified and collected, and time points reported

5. Notes: funding for trial and notable conflicts of interest of trial authors

Two review authors (KK and SB) will independently extract outcome data from included studies, noting in the 'Characteristics of included studies' table if outcome data were not reported in a usable way. We will resolve any disagreements by consensus or by involving a third person (SA). One review author (KK) will transfer data into the RevMan (Review Manager 2014) file, doublechecking that data are entered correctly by comparing the data presented in the systematic review with the study reports. A second review author (SB) will spot-check study characteristics for accuracy against the trial report.

\section{Assessment of risk of bias in included studies}

Two review authors (KK and SB) will independently assess the risk of bias for each study using the criteria outlined in the Cochrane Handbook for Systematic Reviews of Interventions (Higgins 2011), resolving any disagreements by discussion or by involving a third person (SA). We will assess the risk of bias according to the following domains:

1. Random sequence generation

2. Allocation concealment

3. Blinding of participants and personnel

4. Blinding of outcome assessment

5. Incomplete outcome data

6. Selective outcome reporting

7. Other bias

We will grade each potential source of bias as high, low, or unclear and provide a quote from the study report together with a justification for our judgement in the 'Risk of bias' table. We will summarise the 'Risk of bias' judgements across different studies for each of the domains listed. We will consider blinding separately for different key outcomes where necessary (for example for unblinded outcome assessment, risk of bias for all-cause mortality may be very different than for a patient-reported pain scale). Where information on risk of bias is related to unpublished data or correspondence with a study author, we will note this in the 'Risk of bias' table.

Where there are uncertainties due to insufficient reporting, we will contact the study author or sponsor for additional information.

When considering treatment effects, we will take into account the risk of bias for the studies that contributed to that outcome.

\section{Assessment of bias in conducting the systematic review}

Where possible, we conducted the review according to this published protocol and have reported any deviations from it in the 'Differences between protocol and review' section of the systematic review.

\section{Measures of treatment effect}

We will follow the methods below for future updates of this review if we identify randomised trials.

We will analyse dichotomous data as odds ratios and continuous data as mean difference or standardised mean difference. We will enter data presented as a scale with a consistent direction of effect and narratively describe skewed data reported as medians and interquartile ranges.

We will undertake meta-analyses only where this is meaningful, that is if the treatments, participants, and the underlying clinical question are similar enough for pooling to make sense.

Where multiple trial arms are reported in a single trial, we will include only the relevant arms. If two comparisons (for example drug A versus placebo and drug B versus placebo) were combined in the same meta-analysis, we will half the control group to avoid double-counting.

If change from baseline and endpoint scores are available for continuous data, we will use change from baseline unless the majority of studies report endpoint scores. If a study reports outcomes at multiple time points, we will use the end-of-study measurement. When an analysis using only participants who completed the trial and an analysis that imputed data for participants who were randomised but did not provide endpoint data (for example last observation carried forward) are both available, we will use the latter.

\section{Unit of analysis issues}

For dichotomous outcomes, we will use participants rather than events as the unit of analysis (that is number of children admitted

Stopping long-acting beta2-agonists (LABA) for children with asthma well controlled on LABA and inhaled corticosteroids (Review) 
to hospital rather than number of admissions per child). However, if exacerbations are reported as rate ratios, we will also analyse them on this basis.

\section{Dealing with missing data}

If we can include studies in future updates, we will contact investigators or study sponsors to verify key study characteristics and obtain missing numerical outcome data where possible (for example when we identify a study as abstract only). Where this is not possible, and the missing data are thought to introduce serious bias, we will explore the impact of including such studies on the overall assessment of results by a sensitivity analysis.

\section{Assessment of heterogeneity}

We will use the $\mathrm{I}^{2}$ statistic to measure heterogeneity among the trials in each analysis. If we identify substantial heterogeneity, we will report it and explore possible causes by prespecified subgroup analysis.

\section{Assessment of reporting biases}

If we are able to pool more than 10 trials, we will create and examine a funnel plot to explore possible small-study and publication biases. We will consider the impact of unpublished trials in the GRADE ratings for each outcome.

\section{Data synthesis}

If we can include studies in future updates, we will use a randomeffects model for all analyses, as we expect variation in effects due to differences in study populations and methods. We will perform sensitivity analyses with a fixed-effect model.

\section{'Summary of findings' table}

While there were no included studies, we created a Summary of findings for the main comparison to illustrate the lack of evidence for the seven prespecified outcomes. If we can include studies in future updates, we will present the pooled analysis in each case, and note any significant differences between subgroups in the comments column. We will use the five GRADE considerations (study limitations, consistency of effect, imprecision, indirectness, and publication bias) to assess the quality of a body of evidence as it relates to the studies that contribute data to the meta-analyses for the prespecified outcomes. We will use methods and recommendations described in Section 8.5 and Chapter 12 of the Cochrane Handbook for Systematic Reviews of Interventions using GRADEpro software (Higgins 2011). We will justify all decisions to down- or upgrade the quality of studies using footnotes, and we will make comments to aid the reader's understanding of the review where necessary.

\section{Subgroup analysis and investigation of heterogeneity}

If we identify trials in future updates of this review, we will carry out the following subgroup analyses for the primary outcomes, using the formal test for subgroup differences in Review Manager 2014:

1. Mean steroid dose (defined as low, medium, and high cutoffs according to GINA 2014)

2. Type of inhaler used in the comparison group (ICS plus LABA combination inhaler versus separate inhalers)

3. Type and dose of LABA being stopped (formoterol, salmeterol, vilanterol)

Mean steroid dose of the population in each study may reflect differences in disease severity and may have an effect on outcomes after stopping LABA therapy. We will use the boundaries for low, medium, and high dose (ex-actuator) described in GINA 2014.

Participants using combination inhalers might be less likely to experience potential adverse effects of LABA treatment, since there is no danger of taking the LABA inhaler without ICS. Combination inhalers may also be associated with generally better compliance with treatment.

There may be differences in stopping different types of LABA due to their different pharmacological properties and durations of action.

\section{Sensitivity analysis}

We will carry out the following sensitivity analyses for the primary analyses, by excluding the following:

1. Studies at high risk of bias for blinding

2. Unpublished data (i.e. no peer-reviewed full paper available)

\section{RES U L T S}

\section{Description of studies}

\section{Results of the search}

We retrieved 400 records in the main database search, and searches of the additional resources (clinicaltrials.gov, WHO trials portal, reference lists, and drug company registries) returned a total of 634 records. After removing duplicates, we screened 1031 references. We excluded 988 from the title and abstracts alone. We assessed 43 full-text articles (belonging to 23 studies) for inclusion in either this review or the equivalent adult review, which is being produced in parallel. Of these, 22 made the wrong comparison, 16 were adult studies and were included in the respective review, and 4 were classified as ongoing studies or studies awaiting classification in the adult review. The one remaining study was a single-group observational study. 


\section{Included studies}

No studies met the inclusion criteria.

\section{Excluded studies}

We excluded 23 studies (44 citations), mostly because the comparison was incorrect $(\mathrm{n}=22)$ or an adult population was studied $(\mathrm{n}=18)$.

Studies were excluded due to wrong comparison usually because they tested ICS plus LABA against LABA, but were not assessing the question of stopping LABA in a well-controlled population. Of the studies excluded due to the population age but meeting all other inclusion criteria, several included adolescent participants (from 15 or 16 years of age) but did not report data separately for those under 18 (Berger 2010; GSK SAS40037; Koenig 2008).

We excluded three records because their study design did not meet the inclusion criteria: one adult cross-over study with two associated citations and one study asking the right clinical question in children using a single-group observational design (GSK SMS30046; NTR2045).

We identified one other study recruiting adults and adolescents from age 12 and with a planned enrolment of 450 on clinicaltrials.gov and recorded it as an ongoing study (NCT01437995). We hope we can obtain disaggregated data for the adolescents in this study when the results are published.

\section{Risk of bias in included studies}

There were no included studies to assess for risk of bias.

\section{Effects of interventions}

See: Summary of findings for the main comparison

There were no effects of interventions as no randomised trials met the inclusion criteria.

\section{I SCUSSIO N}

\section{Summary of main results}

We conducted extensive searches for trials that randomised children with well-controlled asthma to either stop their LABA or to continue taking combination ICS plus LABA.

Despite conducting extensive additional searches, we identified no trials matching the inclusion criteria.

After removing duplicates, we screened 1031 abstracts and assessed 43 full-text articles for inclusion. We identified several adult studies, which have been summarised in a separate review. The most common reason for exclusion after viewing full-texts were 'wrong comparison' and 'adult population'.

Of the studies excluded due to the population age but meeting all other inclusion criteria, several included adolescent participants, but did not report data separately for those under 18 (Berger 2010; GSK SAS40037; Koenig 2008). One study asking the right clinical question in children was identified on the WHO trials portal, but it was a single-group observational design (NTR2045).

We identified one other study recruiting adults and adolescents from age 12 and with a planned enrolment of 450 on clinicaltrials.gov and recorded it as an ongoing study (NCT01437995). We hope we can obtain disaggregated data for the adolescents in this study when the results are published.

\section{Overall completeness and applicability of evidence}

We identified no trials making the specified comparison in children, which represents an important evidence gap considering the recommendations to stop LABA once control is achieved. It is not clear why this important issue has not been addressed in randomised trials, particularly as several have been conducted in adults. Since we do not know how stopping LABA affects symptom control or the likelihood of adverse outcomes in children, it would be ethical to randomise children to stop or continue LABA treatment. Randomised, double-blinded evidence from trials of at least six months may prevent future adverse events and poor asthma control by informing clinicians of the benefits and harms of stopping LABA relative to continuing.

It is likely that future updates of this review will include data from ongoing trials conducted in populations of adults and adolescents with asthma. This evidence, if disaggregated data can be obtained, will provide important information regarding the applicability of adult evidence to younger populations. However, no published or ongoing trials have yet included children younger than age 12, and there may be different safety issues in this younger group of people with asthma.

\section{Quality of the evidence}

We excluded no trials in this review, but we conducted comprehensive searches that two review authors sifted independently. We excluded no trials for not meeting our inclusion criteria relating to duration or comedications, and there were no disagreements between review authors over their decisions to exclude. In line with Cochrane methods, we excluded no trials on the basis of language, publication status, or the outcomes reported, so we are confident that we would have identified and included any relevant randomised evidence. 


\section{Potential biases in the review process}

The Cochrane Airways Group's Trials Search Co-ordinator designed and conducted the main electronic search, and two review authors discussed and sifted in duplicate additional searches. A paediatrician $(\mathrm{SB})$ with expert knowledge in the area reviewed the potentially relevant records.

We did not attempt to obtain disaggregated data from the three adult trials that met the inclusion criteria and included adolescents between the age of 15 and 18 . Since 15 and 16 were the lower age limits in these trials, and the mean ages were between 38 and 41, we concluded that the number of adolescent participants would be small and not necessarily representative of children and adolescents in general.

\section{Agreements and disagreements with other studies or reviews}

Two systematic reviews have assessed this question, but neither were able to comment specifically on evidence for adolescents and children. While one non-Cochrane review looked for studies in adults and children (Brozek 2012), and a Cochrane review looked solely for adult studies (Ahmad 2014), the two reviews included the same five studies in meta-analysis and reached similar conclusions. Brozek 2012 noted the lack of evidence for children and the inclusion of older children and adolescents ( 15 years and over) in several of the trials, but without individual participant data in larger and longer trials, it is not possible to judge whether the older children within the adult studies had different outcomes, and there is no information for younger children.

Both reviews concluded that the evidence for adults and older children suggests a clear loss of symptom control after stopping LABA on several measures. Both reviews suggested that even the evidence base for adults and older children is incomplete; there were infrequent events for some of the most important outcomes (for example exacerbations requiring hospital admission, serious adverse events, and mortality), a small number of trials contributing to several of the meta-analyses, and relatively short follow-up times. This paucity of evidence also precluded any meaningful subgroup analyses to explore possible effect modifiers such as ICS dose and type of LABA. There is a total lack of information for children under 15 years of age.

\section{A U THORS'CONCLUSIONS}

\section{Implications for practice}

There is currently no evidence from randomised trials to inform LABA discontinuation in children once asthma control is achieved with ICS plus LABA.

The only randomised evidence for stopping LABA has been conducted in adults, and will be summarised in a separate review (Ahmad 2014). Evidence from an ongoing trial recruiting adults and children over age 12 may provide some initial evidence for older children.

\section{Implications for research}

A double-blind randomised trial to assess this question would help clinicians judge when it is safe and beneficial to stop LABA in children. The study should be large enough to assess children of different ages, and measure the important safety and efficacy outcomes suggested in this review over at least six months.

\section{ACKNOW LEDGEMENTS}

We would like to thank Rebecca Normansell, who contributed to the related protocol and review addressing this question in adults (Ahmad 2014), which informed the design of this review. We also thank Elizabeth Stovold for designing the search strategy and running the main electronic searches.

Jimmy Chong was the Editor for this review and commented critically on the review.

The Background and Methods sections of this review are based on a standard template used by the Cochrane Airways Group.

Cochrane Review Group funding acknowledgement: The National Institute for Health Research (NIHR) is the largest single funder of the Cochrane Airways Group.

Disclaimer: The views and opinions expressed herein are those of the review authors and do not necessarily reflect those of the NIHR, the National Health Service or the Department of Health. 


\section{R E F E R E N C E S}

\section{References to studies excluded from this review}

Aalbers 2005 \{published data only\}

Aalbers R, Harris A, Naya I. Adjustable dosing with budesonide/formoterol achieves sustained guideline 'wellcontrolled asthma' following step down in treatment [Abstract]. European Respiratory Journal 2005;26:A431.

Berger 2010 \{published and unpublished data\}

AstraZeneca. A 12-week randomized, double-blind, doubledummy, placebo- and active-controlled study of Symbicort pMDI administered once daily in adults and adolescents with asthma. http://www.astrazenecaclinicaltrials.com/ (accessed 10 September 2014). [AstraZeneca: SD-0390726]

Berger WE, Bleecker ER, O’Dowd L, Miller CJ, Mezzanotte W. Efficacy and safety of budesonide/formoterol pressurized metered-dose inhaler: randomized controlled trial comparing once- and twice-daily dosing in patients with asthma. Allergy and Asthma Proceedings 2010;31(1):49-59.

Bumbacea 2010 \{published data only\} Bumbacea D, Dymek A, Mansikka H. P16 Fluticasone propionate/formoterol fumarate combination therapy has an efficacy and safety profile similar to that of its individual components administered concurrently: A randomised controlled trial [Abstract]. Thorax 2010;65((Suppl 4)):A83.

Cowie 2007 \{published data only\}

Cowie RL, Boulet LP, Keith PK, Scott-Wilson CA, House KW, Dorinsky PM. Tolerability of a salmeterol xinafoate/ fluticasone propionate hydrofluoroalkane metered-dose inhaler in adolescent and adult patients with persistent asthma: a 52-week, open-label, stratified, parallel-group, multicenter study. Clinical Therapeutics 2007;29(7): 1390-402.

FitzGerald 2003 \{published data only\} FitzGerald JM, Sears MR, Boulet LP, Becker AB. Erratum: Adjustable maintenance dosing with budesonide/formoterol reduces asthma exacerbations compared with traditional fixed dosing: A five month multicentre Canadian study [Canadian Respiratory Journal (2003) vol. 10 (8) (427434)]. Canadian Respiratory Journal [Revue canadienne de pneumologie] 2004;11(1):20.

FitzGerald JM, Sears MR, Boulet LP, Becker AB, McIvor AR, Ernst P, et al. Adjustable maintenance dosing with budesonide/formoterol reduces asthma exacerbations compared with traditional fixed dosing: A five-month multicentre Canadian study. Canadian Respiratory Journal [Revue canadienne de pneumologie] 2003;10(8):427-34.

Fowler 2002 \{published data only\}

Fowler SJ, Currie GP, Lipworth BJ, Currie PC. Step-down therapy with low-dose fluticasone-salmeterol combination or medium-dose hydrofluoroalkane 134a-beclomethasone alone. Journal of Allergy and Clinical Immunology 2002;109 (6):929-35.
Godard 2008 \{published and unpublished data\}

GlaxoSmithKline. Maintenance of asthma control in adults: comparison of three therapeutic strategies in patients whose asthma is controlled by a medium dose of inhaled corticosteroid and a long-acting inhaled 2-agonist. http:// www.gsk-clinicalstudyregister.com/ (accessed 10 September 2014).

Godard P, Attali V. Comparison of different treatment strategies in stepping down combination treatment withdrawing the LABA versus reducing the ICS dose [Abstract]. Proceedings of the American Thoracic Society 2006;3(3):A213.

* Godard P, Greillier P, Pigearias B, Nachbaur G, Desfougeres J-L, Attali V. Maintaining asthma control in persistent asthma: comparison of three strategies in a 6month double-blind randomised study. Respiratory Medicine 2008;102(8):1124-31.

GSK ADA109315 \{unpublished data only\} GSK ADA109315. A retrospective study of healthcare utilization and costs of step-down therapy in asthma patients receiving fluticasone propionate/salmeterol combination. www.gsk-clinicalstudyregister.com/files2/26012.pdf (accessed 9 December 2014).

GSK SAS40037 \{unpublished data only\}

* GlaxoSmithKline. Randomized, double-blind, doubledummy, parallel group, 16-week comparison of asthma control in adolescents and adults receiving either fluticasone propionate/salmeterol Diskus combination product 100/ $50 \mathrm{mcg}$ BID, fluticasone propionate Diskus $100 \mathrm{mcg}$ BID, salmeterol xinafoate Diskus $50 \mathrm{mcg}$ BID, or oral montelukast $10 \mathrm{mg}$ Q. www.gsk-clinicalstudyregister.com/ (accessed 10 September 2014).

Oppenheimer J, Stauffer J, Waitkus-Edwards K, Yancey S, Prillaman B, Sutton L, et al. "Stepping down" from fluticasone propionate/salmeterol 100/50mcg Diskus results in loss of asthma control. American Thoracic Society 100th International Conference; 2004 May 21-26; Orlando. 2004:J94.

GSK SMS30046 \{unpublished data only\} GSK SMS30046. Effects of long-term administration of salmeterol on clinical symptoms, inhaled corticosteroid requirement and bronchial reactivity, and the effect of stopping long-term salmeterol treatment. www.gskclinicalstudyregister.com/study/SMS30046\#rs (accessed 8 December 2014).

Wilding P, Clark M, Thompson Coon J, Lewis S, Rushton $\mathrm{L}$, Bennett J, et al. Effect of long-term treatment with salmeterol on asthma control: a double blind, randomised crossover study. BMJ 1997;314(7092):1441-6.

Harrison 1997 \{published data only\}

Harrison TW, Oborne J, Wilding PJ, Tattersfield AE. A controlled trial of beta2-agonist dose reduction in asthmatic patients on high doses of beta2-agonist [Abstract]. European Respiratory Journal 1997;10(Suppl 25):3S. 
Ind 2004 \{published data only\}

Ind PW, Haughney J, Price D, Rosen JP, Kennelly J. Adjustable and fixed dosing with budesonide/formoterol via a single inhaler in asthma patients: the ASSURE study. Respiratory Medicine 2004;98(5):464-75.

Koenig 2008 \{published and unpublished data\}

Dorinsky P, Stauffer J, Waitkus-Edwards K, Yancey S, Prillaman B, Sutton L. Stepping down from fluticasone propionate/salmeterol 100/50mcg Diskus results in loss of asthma control [Abstract]. European Respiratory Journal 2004;24((suppl 48)):309s.

Dorinsky PM, Stauffer J, Waitkus-Edwards K, Yancey S, Prillaman BA, Sutton L. "Stepping down" from fluticasone propionate/salmeterol 100/50mcg Diskus(R) results in loss of asthma control: lack of effect of ethnic origin [Abstract]. Chest 2004;126((4 Suppl)):758S-a.

GlaxoSmithKline. A multicenter, randomized, doubleblind, double-dummy, parallel group, 16-week comparison of asthma control in adolescents and adults receiving either fluticasone propionate/salmeterol Diskus combination product $100 / 50 \mathrm{mcg}$ BID, fluticasone propionate Diskus 100 mcg BID, salmeterol xinafoate Diskus 50 mcg BID, or oral montelukast 10mg QD. www.gskclinicalstudyregister.com/ (accessed 10 September 2014). Koenig S, Waitkus-Edwards K, Yancey S, Prillaman B, Dorinsky P. Loss of asthma control when patients receiving fluticasone propionate/salmeterol 100/50 $\mathrm{g}$ g Diskus are "stepped down" to fluticasone propionate, salmeterol or montelukast alone. Journal of Allergy and Clinical Immunology 2004;113(2):S94.

* Koenig SM, Ostrom N, Pearlman D, Waitkus-Edwards K, Yancey S, Prillaman BA, et al. Deterioration in asthma control when subjects receiving fluticasone propionate/ salmeterol 100/50 mcg Diskus are 'stepped-down'. Journal of Asthma 2008;45(8):681-7.

Liu 2007 \{published data only\}

Liu CT, Wang YM, Wang G, Tan CW, Pang YM. A clinical study on the significance of airway hyperresponsiveness monitoring in the adjustment of combined therapy for asthmatic patients. Zhonghua jie he he hu xi za zhi [Chinese Journal of Tuberculosis and Respiratory Diseases] 2007;30(7): 498-503.

Nathan 2009 \{published data only\}

Nathan R, Pearlman D, Nayak A, Nolte H. Safety and tolerability of medium-dose mometasone furoate/ formoterol treatment versus mometasone furoate or formoterol monotherapies in persistent asthmatics who previously used medium-dose inhaled corticosteroids (alone or with long-acting beta2-agonist) [Abstract]. Chest 2009; 136(4):8S

Nathan R, Pearlman D, Nolte H, Nayak A. Safety and tolerability of mometasone furoate/formoterol for persistent asthma subjects who previously were treated with mediumdose inhaled corticosteroids (alone or with a long-acting beta2-agonist) [Abstract]. Annals of Allergy, Asthma \& Immunology 2009;103(4):A58.
NCT00158834 \{unpublished data only\}

* NCT00158834. Pediatric asthma study using stepwise treatment with two Food and Drug Administration approved asthma medications. www.clinicaltrials.gov/ct2/ show/study/NCT00158834 (accessed 5 December 2014).

NCT01565031 \{unpublished data only\}

NCT01565031. Prediction of future risk in patients with controlled asthma. https://clinicaltrials.gov/show/ NCT01565031 (accessed 9 December 2014).

\section{NCT02094937 \{unpublished data only\}}

NCT02094937. A study to compare the efficacy and safety of fluticasone furoate (FF) $100 \mathrm{mcg}$ once daily with fluticasone propionate (FP) $250 \mathrm{mcg}$ twice daily (BD) and FP $100 \mathrm{mcg}$ BD in well-controlled asthmatic Japanese subjects. https://clinicaltrials.gov/ct2/show/NCT02094937 (accessed 9 September 2014).

NTR2045 \{unpublished data only\}

* Kersten E. The effect of stepping down asthma therapy in clinically stable children on exercise induced asthma. www.trialregister.nl/trialreg/admin/rctview.asp?TC=2045 (accessed 5 December 2014).

\section{Obase 2013 \{published data only\}}

Obase Y, Ikeda M, Kurose K, Abe M, Shimizu H, Ohue Y, et al. Step-down of budesonide/formoterol in early stages of asthma treatment leads to insufficient anti-inflammatory effect. Journal of Asthma 2013;50(7):718-21.

Paggiaro 2011 \{published data only\} Paggiaro P, Nicolini G, Crimi N, Fabbri L, Olivieri D, Rossi A, et al. Six months step down treatment from high dose ICS/LABA combination therapy in asthma [Abstract]. American Journal of Respiratory and Critical Care Medicine 2011;183(Meeting Abstracts):A1278.

Paggiaro P, Nicolini G, Crimi N, Fabbri LM, Olivieri D, Rossi A, et al. Asthma control and lung function after step down from high dose ICS/LABA combination therapy [Abstract]. European Respiratory Journal 2011;38(suppl 55): 722s [P3967].

Papi 2012 \{published data only\}

NCT00497237. Prospective, randomised, open-label, multicentre, active drug controlled, parallel group design clinical trial of the efficacy and safety of beclomethasone dipropionate $400 \mathrm{Mcg}$ + formoterol $24 \mathrm{mcg}$ pMDI via HFA-134a (Foster ${ }^{\mathrm{TM}}$ ) vs. fluticasone propionate $500 \mathrm{mcg}$ + salmeterol xinafoate $100 \mathrm{mcg}$ DPI (Seretide Diskus ${ }^{\circledR}$ ) in the 6 months stepdown treatment of adult patients with controlled asthma. https://clinicaltrials.gov/show/ NCT00497237 (accessed 9 December 2014).

Papi A, Nicolini G, Crimi N, Fabbri L, Olivieri D, Rossi A, et al. Step-down from high dose fixed combination therapy in asthma patients: a randomized controlled trial. Respiratory Research 2012;13:54.

Reddel 2010 \{published and unpublished data\}

GlaxoSmithKline. A 13-month, randomised, doubleblind, parallel-group comparison of the efficacy of Seretide (fluticasone propionate/salmeterol combination Accuhaler) and Flixotide (fluticasone propionate Accuhaler) 
when down-titrating the inhaled corticosteroid dose in asthmatic adults who have previously received Seretide $500 / 50 \mathrm{mcg}$ twice daily for at least 4wk. www.gskclinicalstudyregister.com/ (accessed 10 September 2014). * Reddel HK, Gibson PG, Peters MJ, Wark PAB, Sand IB, Hoyos CM, et al. Down-titration from high-dose combination therapy in asthma: Removal of long-acting beta(2)-agonist. Respiratory Medicine 2010;104(8): 1110-20.

Reddel HK, Peyters MJ, Wark PA, Sand IB, Jenkins CR. Comparison of the efficacy of Seretide and Flixotide when down-titrating the inhaled corticosteroid dose. Thoracic Society of Australia and New Zealand Annual Scientific Meeting; 2007 Mar 25-28; Auckland. 2007:TP041.

Self 1998 \{published data only\}

Rumbak M, Self T, Kelso T, Eberle L, Abou-Shala $\mathrm{N}$, Learned S, et al. Moderate to high dose inhaled corticosteroids in adult asthmatics: does salmeterol facilitate step down therapy? [Abstract]. European Respiratory Journal 1998;12((Suppl 29)):19s.

Self T, Rumbak MJ, Kelso T, Eberle L, Abou Shala N, Learned CC, et al. Does salmeterol facilitate 'step-down' therapy in patients with asthma receiving moderate to high doses of inhaled corticosteroids?. Current Therapeutic Research, Clinical and Experimental 1998;59(11):803-11.

Shamsul 2007 \{published data only\}

Shamsul AI, Hadzri HM, Noradina AT, Fauzi MA, Hamid AJ, Rosalina AM, et al. Step-down approach in chronic stable asthma; a comparison of reducing dose inhaled formoterol/budesonide with maintaining inhaled budesonide [Abstract]. Respirology 2007;12(s4):A141.

Slankard 2011 \{published and unpublished data\}

* Slankard ML, Canfield S, Michelis M, Mansukhani M, McGoey B, Paige A, et al. ADRB2 (adrenergic B2 receptor agonist gene) Arg 16 allele and effect of LABA withdrawal in patients with moderate to severe asthma [Abstract]. Journal of Asthma and Clinical Immunology (Proceedings of the AAAAI Annual Meeting 2011) 2011;127(2):AB67.

Zangrilli 2009 \{published data only\}

Zangrilli J, Uryniak T, O'Brien CD. Efficacy of budesonide/ formoterol (BUD/FM) vs BUD in Hispanic patients: Differential results when including run-in lung function vs controller history and run-in symptoms [Abstract]. Annals of Allergy, Asthma and Immunology 2009;103:5.

\section{References to ongoing studies}

\section{NCT01437995 \{unpublished data only\}}

NCT01437995. Long-acting beta agonist step down study (LASST). Available from http://clinicaltrials.gov/show/ NCT01437995 (accessed 10 September 2014).

\section{Additional references}

\section{Adams 2005}

Adams NP, Bestall JB, Malouf R, Lasserson TJ, Jones PW. Beclomethasone versus placebo for chronic asthma.
Cochrane Database of Systematic Reviews 2005, Issue 1. [DOI: 10.1002/14651858.CD002738.pub2]

Adams 2009

Adams NP, Bestall JC, Lasserson TJ, Jones P, Cates CJ. Fluticasone versus placebo for chronic asthma in adults and children. Cochrane Database of Systematic Reviews 2009, Issue 4. [DOI: 10.1002/14651858.CD003135.pub4]

\section{Ahmad 2014}

Ahmad S, Kew KM, Normansell R. Stopping longacting beta2-agonists (LABA) for adults with asthma wellcontrolled on LABA and inhaled corticosteroids. Cochrane Database of Systematic Reviews 2014, Issue 9. [DOI: 10.1002/14651858.CD011306]

\section{Anderson 2005}

Anderson HR. Prevalence of asthma. BMJ 2005;330:1037.

\section{Australian Asthma Handbook 2014}

National Asthma Council Australia. Australian Asthma Handbook 2014, Version 1.0. www.asthmahandbook.org.au (accessed 28 July 2014). [ISSN: 2203-4722]

Barnes 1993

Barnes PJ, Adcock I. Anti-inflammatory actions of steroids: molecular mechanisms. Trends in Pharmacological Sciences 1993;14:436-41.

\section{Bijl-Hofland 2001}

Bijl-Hofland ID, Cloosterman SG, Folgering HT, van den Elshout FJ, van Weel C, van Schayck CP. Inhaled corticosteroids, combined with long-acting beta2-agonists, improve the perception of bronchoconstriction in asthma. American Journal of Respiratory and Critical Care Medicine 2001;164(5):764-9.

Brown 1983

Brown MJ, Brown DC, Murphy MB. Hypokalemia from beta2-receptor stimulation by circulating epinephrine. The New England Journal of Medicine 1983;309(23):1414-9.

\section{Brozek 2012}

Brozek JL, Kraft M, Krishnan JA, Cloutier MM, Lazarus SC, Li JT, et al. Long-acting $\beta_{2}$-agonist step-off in patients with controlled asthma. Archives of Internal Medicine 2012; 172(18):1365-75.

\section{BTS 2011}

British Thoracic Society. Adult asthma audit report 2011. www.brit-thoracic.org.uk/audit-and-quality-improvement/ (accessed 9 June 2014).

\section{BTS/SIGN 2012}

British Thoracic Society/Scottish Intercollegiate Guidelines Network (BTS/SIGN). British Guideline on the Management of Asthma. http://www.brit-thoracic.org.uk/ guidelines/asthma-guidelines.aspx (accessed 6 June 2014).

\section{Bush 2009}

Bush A, Menzies-Gow A. Phenotypic differences between pediatric and adult asthma. Proceedings of the American Thoracic Society 2009;6(8):712-9. 


\section{Cates 2012a}

Cates CJ, Cates MJ. Regular treatment with formoterol for chronic asthma: serious adverse events. Cochrane Database of Systematic Reviews 2012, Issue 4. [DOI: 10.1002/ 14651858.CD006923.pub3]

\section{Cates 2012b}

Cates CJ, Oleszczuk M, Stovold E, Wieland LS. Safety of regular formoterol or salmeterol in children with asthma: an overview of Cochrane reviews. Cochrane Database of Systematic Reviews 2012, Issue 10. [DOI: 10.1002/ 14651858.CD010005.pub2]

\section{Cates 2014}

Cates CJ, Wieland LS, Oleszczuk M, Kew KM. Safety of regular formoterol or salmeterol in adults with asthma: an overview of Cochrane reviews. Cochrane Database of Systematic Reviews 2014, Issue 2. [DOI: 10.1002/ 14651858.CD010314.pub2]

\section{Crane 1989}

Crane J, Pearce N, Flatt A, Burgess C, Jackson R, Kwong T, et al. Prescribed fenoterol and death from asthma in New Zealand. The Lancet 1989;1(8644):917-22.

\section{Ducharme 2008}

Ducharme FM, Ni Chroinin M, Greenstone I, Lasserson TJ. Addition of long-acting beta2-agonists to inhaled corticosteroids versus same dose inhaled corticosteroids for chronic asthma in adults and children. Cochrane Database of Systematic Reviews 2008, Issue 5. [DOI: 10.1002/ 14651858.CD005535.pub2]

\section{Ducharme 2010}

Ducharme FM, Ni Chroinin M, Greenstone I, Lasserson TJ. Addition of long-acting beta2-agonists to inhaled steroids versus higher dose inhaled steroids in adults and children with persistent asthma. Cochrane Database of Systematic Reviews 2010, Issue 4. [DOI: 10.1002/ 14651858.CD005533.pub2]

\section{Ernst 2006}

Ernst P, McIvor A, Ducharme FM, Boulet LP, Fitzgerald $M$, Chapman KR, et al. Safety and effectiveness of longacting inhaled beta-agonist bronchodilators when taken with inhaled corticosteroids. Annals of Internal Medicine 2006;146(9):692-4.

\section{FDA 2010}

United States Food, Drug Administration. FDA News Release: FDA Announces New Safety Controls for Long-Acting Beta Agonists, Medications Used to Treat Asthma. http://www.fda.gov/NewsEvents/Newsroom/ PressAnnouncements/ucm200931.htm (accessed 6 May 2015).

\section{GINA 2009}

Global Initiative for Asthma. Global Strategy for the Diagnosis and Management of Asthma in Children 5 Years and Younger. http://www.ginasthma.org/GlobalStrategy-for-the-Diagnosis-and-Management-of-Asthmain-Children-5-Years-and-Younger (accessed 28 July 2014).

\section{GINA 2014}

Global Initiative for Asthma (GINA). From the Global Strategy for Asthma Management and Prevention, Global Initiative for Asthma (GINA) 2014. http://www.ginasthma.org/local/uploads/files/ GINA`Report' 2014'Jun11.pdf (accessed 19 June 2014).

\section{Global Asthma Report 2011}

International Union Against Tuberculosis and Lung Disease. The Global Asthma Report 2011. Available from http:/ /www.theunion.org/what-we-do/publications/technical/ global-asthma-report (accessed 4 Aug 2014).

\section{Hernández 2014}

Hernández G, Avila M, Pont A, Garin O, Alonso J, Laforest L, et al. Long-acting beta-agonists plus inhaled corticosteroids safety: a systematic review and meta-analysis of non-randomized studies. Respiratory Research 2014;15: 83.

\section{Higgins 2011}

Higgins JPT, Green S (editors). Cochrane Handbook for Systematic Reviews of Interventions Version 5.1 [updated March 2011]. The Cochrane Collaboration. www.cochrane-handbook.org.

\section{Johnston 2009}

Johnston SL, Edwards MR. Mechanisms of adverse effects of beta-agonists in asthma. Thorax 2009;64(9):739-41.

\section{Lemanske 2011}

Lemanske RF, Mauger DT, Sorkness CA, Jackson DJ, Boehmer SJ, Martinez FD, et al. Step-up therapy for children with uncontrolled asthma receiving inhaled corticosteroids. The New England Journal of Medicine 2010; 362:975-85.

\section{Lipworth 1997}

Lipworth BJ. Airway subsensitivity with long-acting beta2agonists: is there a cause for concern?. Drug Safety 1997;16 (5):295-30.

\section{McMahon 2011}

McMahon AW, Levenson MS, McEvoy BW, Mosholder

AD. Age and risks of FDA-approved long-acting $\beta 2$ adrenergic receptor agonists. Pediatrics 2011;128(5): e1147-54.

\section{NAEPP 2007}

National Asthma Education and Prevention Program. Guidelines for the Diagnosis and Management of Asthma. www.nhlbi.nih.gov/guidelines/asthma/asthgdln.pdf (accessed 6 June 2014).

\section{NCT01462344}

NCT01462344. 6-month Safety and Benefit Study of ADVAIR in Children 4-11 Years Old (VESTRI). https:// www.clinicaltrials.gov/ct2/show/NCT01462344 (accessed 29 June 2012).

\section{Nelson 1995}

Nelson HS. Beta-adrenergic bronchodilators. The New England Journal of Medicine 1995;333(8):449-506. 


\section{Nelson 2006}

Nelson HS, Weiss ST, Bleecker ER, Yancey SW, Dorinsky PM, SMART Study Group. The salmeterol multicenter asthma research trial. Chest 2006;129:15-26.

\section{Ni Chroinin 2009}

Ni Chroinin M, Lasserson TJ, Greenstone I, Ducharme FM. Addition of long-acting beta-agonists to inhaled corticosteroids for chronic asthma in children. Cochrane Database of Systematic Reviews 2009, Issue 3. [DOI: 10.1002/14651858.CD007949]

\section{NRAD 2014}

Royal College of Physicians. Why asthma still kills: the national review of asthma deaths. https:// www.rcplondon.ac.uk/sites/default/files/why-asthma-stillkills-full-report.pdf (accessed 28 August 2014).

\section{Oppenheimer 2008}

Oppenheimer J, Nelson HS. Safety of long-acting $\beta$ agonists in asthma: a review. Current Opinion in Pulmonary Medicine 2008;14:64-9.

\section{PHAC 2007}

Public Health Agency of Canada. Life and Breath: Respiratory Disease in Canada. http://www.phacaspc.gc.ca/ (accessed 28 July 2014).

\section{Pruteanu 2014}

Pruteanu AI, Chauhan BF, Zhang L, Prietsch SOM, Ducharme FM. Inhaled corticosteroids in children with persistent asthma: dose-response effects on growth. Cochrane Database of Systematic Reviews 2014, Issue 7. [DOI: 10.1002/14651858.CD009878.pub2]

\section{Review Manager 2014}

The Nordic Cochrane Centre, The Cochrane Collaboration. Review Manager (RevMan). 5.3. Copenhagen: The Nordic Cochrane Centre, The Cochrane Collaboration, 2014.

\section{Salpeter 2006}

Salpeter SR, Buckley NS, Ormiston TM, Salpeter EE. Meta-analysis: effect of long-acting beta-agonists on severe asthma exacerbations and asthma related deaths. Annals of Internal Medicine 2006;144:904-12.

\section{Spycher 2010}

Spycher BD, Silverman M, Kuehni CE. Phenotypes of childhood asthma: are they real?. Experimental Allergy 2010;40:1130-41.

\section{Tattersfield 2006}

Tattersfield AE. Current issues with beta2-adrenoceptor agonists: historical background. Clinical Reviews in Allergy and Immunology 2006;31(2-3):107-18.

\section{Zhang 2011}

Zhang L, Axelsson I, Chung M, Lau J. Dose response of inhaled corticosteroids in children with persistent asthma: a systematic review. Pediatrics 2011;127(1):129-38.

\section{Zhang 2014}

Zhang L, Prietsch SOM, Ducharme FM. Inhaled corticosteroids in children with persistent asthma: effects on growth. Cochrane Database of Systematic Reviews 2014, Issue 7. [DOI: 10.1002/14651858.CD009471.pub2]

* Indicates the major publication for the study 


\section{CHARACTERISTICS OFSTUDIES}

\section{Characteristics of excluded studies [ordered by study ID]}

\begin{tabular}{|c|c|}
\hline Study & Reason for exclusion \\
\hline Aalbers 2005 & Wrong comparison - not stepping down LABA \\
\hline Berger 2010 & Wrong population - adults \\
\hline Bumbacea 2010 & Wrong comparison - not stopping LABA \\
\hline Cowie 2007 & Wrong comparison - not stopping LABA \\
\hline FitzGerald 2003 & Wrong comparison - not stopping LABA \\
\hline Fowler 2002 & Wrong comparison - ICS dose was higher in the step-down group \\
\hline Godard 2008 & Wrong population - adults \\
\hline GSK ADA109315 & $\begin{array}{l}\text { Wrong comparison - not stopping LABA } \\
\text { Analysis of healthcare utilisation and costs of stepping down LABA }\end{array}$ \\
\hline GSK SAS40037 & Wrong population - adults \\
\hline GSK SMS30046 & Wrong study design - cross-over study \\
\hline Harrison 1997 & Wrong comparison - not stopping LABA \\
\hline Ind 2004 & Wrong comparison - not stopping LABA \\
\hline Koenig 2008 & Wrong population - adults \\
\hline Liu 2007 & Wrong population - adults \\
\hline Nathan 2009 & Wrong comparison - not stopping LABA \\
\hline NCT00158834 & $\begin{array}{l}\text { Wrong comparison - not stopping LABA using symptom scores with or without PD20 methacholine to adjust } \\
\text { treatment }\end{array}$ \\
\hline NCT01565031 & Wrong comparison - no clear step-down strategy for LABA \\
\hline NCT02094937 & Wrong population - adults (ongoing trial) \\
\hline NTR2045 & $\begin{array}{l}\text { Wrong study design - single-group observational study } \\
\text { The effect of stepping down from LABA/ICS combination therapy to ICS monotherapy on exercise and } \\
\text { mannitol challenge tests in asthmatic children }\end{array}$ \\
\hline
\end{tabular}


(Continued)

\begin{tabular}{ll}
\hline Obase 2013 & Wrong comparison - not stopping LABA \\
\hline Paggiaro 2011 & Wrong comparison - not stopping LABA \\
\hline Papi 2012 & Wrong comparison - not stopping LABA \\
\hline Reddel 2010 & Wrong population - adults \\
\hline Self 1998 & Wrong comparison - ICS stepped down \\
\hline Shamsul 2007 & Wrong comparison - two step-down groups \\
\hline Slankard 2011 & Wrong population - adults \\
\hline Zangrilli 2009 & Wrong comparison - ICS stepped down \\
\hline
\end{tabular}

\section{Characteristics of ongoing studies [ordered by study ID]}

\section{NCT01437995}

\begin{tabular}{|c|c|}
\hline Trial name or title & Long-acting Beta Agonist Step Down Study (LASST) \\
\hline Methods & $\begin{array}{l}\text { 56-week, multicentre, blinded, randomised, double-masked parallel group comparative effectiveness study of } \\
\text { approaches to stepping down therapy for people with well-controlled asthma treated with combination ICS } \\
\text { and LABA }\end{array}$ \\
\hline Participants & $\begin{array}{l}\text { Inclusion Criteria: males and females aged } 12-80 \text { years with well-controlled asthma on moderate dose ICS/ } \\
\text { LABA based on an Asthma Control Test score } \geq 20 \text {, absence of unscheduled visits or use of rescue prednisone } \\
\text { for } 4 \text { weeks prior to enrolment and a pre-bronchodilator FEV1 } \geq 70 \% \text { predicted } \\
\text { Exclusion Criteria: chronic oral steroid therapy, hospitalisation or urgent care visit within } 4 \text { weeks of the } \\
\text { screening visit, lung disease other than asthma including COPD, bronchiectasis, sarcoidosis, or other lung } \\
\text { disease. Less than } 10 \text { pack/yr of tobacco use and abstinence, post-bronchodilator FEV1 }<70 \% \text { predicted, } \\
\text { near fatal asthma (intubation or ICU admission for asthma) within } 2 \text { yrs of enrolment, high risk of near fatal } \\
\text { or fatal asthma, history of known premature birth less than } 33 \text { weeks or any significant level of respiratory } \\
\text { care including prolonged oxygen administration or mechanical ventilation during the neonatal period, un- } \\
\text { stable cardiac disease (decompensated congestive heart failure, unstable angina, recent myocardial infarction, } \\
\text { atrial fibrillation, supraventricular or ventricular tachycardia, congenital heart disease, or severe uncontrolled } \\
\text { hypertension), other major chronic illnesses, drug allergies, pregnancy, lactation }\end{array}$ \\
\hline
\end{tabular}

Interventions Stepping down from fluticasone/salmeterol Diskus 250/50 mcg twice a day to fluticasone Diskus $250 \mathrm{mcg}$ twice a day without salmeterol

Outcomes

Primary: Rate of treatment failures (decline in peak flow or FEV1, increased need for beta agonists, requirement for non-scheduled medical care for asthma symptoms, or prednisone taper)

Secondary: Pulmonary function (morning peak expiratory flow, pre-bronchodilator FEV1), episodes of poor asthma control defined by unscheduled medical care, hospitalisation, use of oral corticosteroids and/or 


\section{NCT01437995 (Continued)}

increased use of rescue medications and/or decrease of $30 \%$ or more in morning peak expiratory flow rate

Starting date March 2012

Contact information Joy Saams, Registered Nurse

Notes

Estimated enrolment: 450. Estimated study completion date: June 2015

May be able to obtain data for children and adolescents separately from the adult participants 


\section{DATA ANDANALYSES}

This review has no analyses.

\section{A P PENDICES}

\section{Appendix I. Sources and search methods for the Cochrane Airways Group Specialised Register (CAGR)}

Electronic searches: core databases

\begin{tabular}{ll}
\hline Database & Frequency of search \\
\hline CENTRAL (Cochrane Library) & Monthly \\
\hline MEDLINE (Ovid) & Weekly \\
\hline EMBASE (Ovid) & Weekly \\
\hline PsycINFO (Ovid) & Monthly \\
\hline CINAHL (EBSCO) & Monthly \\
\hline AMED (EBSCO) & Monthly \\
\hline
\end{tabular}

\section{Handsearches: core respiratory conference abstracts}

\begin{tabular}{l|l}
\hline Conference & Years searched \\
\hline American Academy of Allergy, Asthma and Immunology (AAAAI) & 2001 onwards \\
\hline American Thoracic Society (ATS) & 2001 onwards \\
\hline Asia Pacific Society of Respirology (APSR) & 2004 onwards \\
\hline British Thoracic Society Winter Meeting (BTS) & 2000 onwards \\
\hline Chest Meeting & 2003 onwards
\end{tabular}


International Primary Care Respiratory Group Congress (IPCRG) 2002 onwards

Thoracic Society of Australia and New Zealand (TSANZ)

1999 onwards

\section{MEDLINE search strategy used to identify trials for the CAGR}

\section{Asthma search}

1. exp Asthma/

2. asthma\$.mp.

3. (antiasthma $\$$ or anti-asthma $\$) . \mathrm{mp}$.

4. Respiratory Sounds/

5. wheez\$.mp.

6. Bronchial Spasm/

7. bronchospas $\$ . m p$.

8. (bronch $\$$ adj3 spasm\$).mp.

9. bronchoconstrict $\$ . m p$.

10. exp Bronchoconstriction/

11. (bronch\$ adj3 constrict\$).mp.

12. Bronchial Hyperreactivity/

13. Respiratory Hypersensitivity/

14. ((bronchial\$ or respiratory or airway $\$$ or lung $\$$ ) adj3 (hypersensitiv\$ or hyperreactiv\$ or allerg $\$$ or insufficiency)).mp.

15. ((dust or mite\$) adj3 (allerg\$ or hypersensitiv\$)).mp.

16. or/1-15

\section{Filter to identify RCTs}

1. exp "clinical trial [publication type]"/

2. (randomised or randomised).ab,ti.

3. placebo.ab,ti.

4. dt.fs.

5. randomly.ab,ti.

6. trial.ab,ti.

7. groups.ab,ti.

8. or/1-7

9. Animals/

10. Humans/

11. 9 not (9 and 10)

12. 8 not 11

The MEDLINE strategy and RCT filter are adapted to identify trials in other electronic databases. 


\section{Appendix 2. Search strategy to identify trial reports from the CAGR}

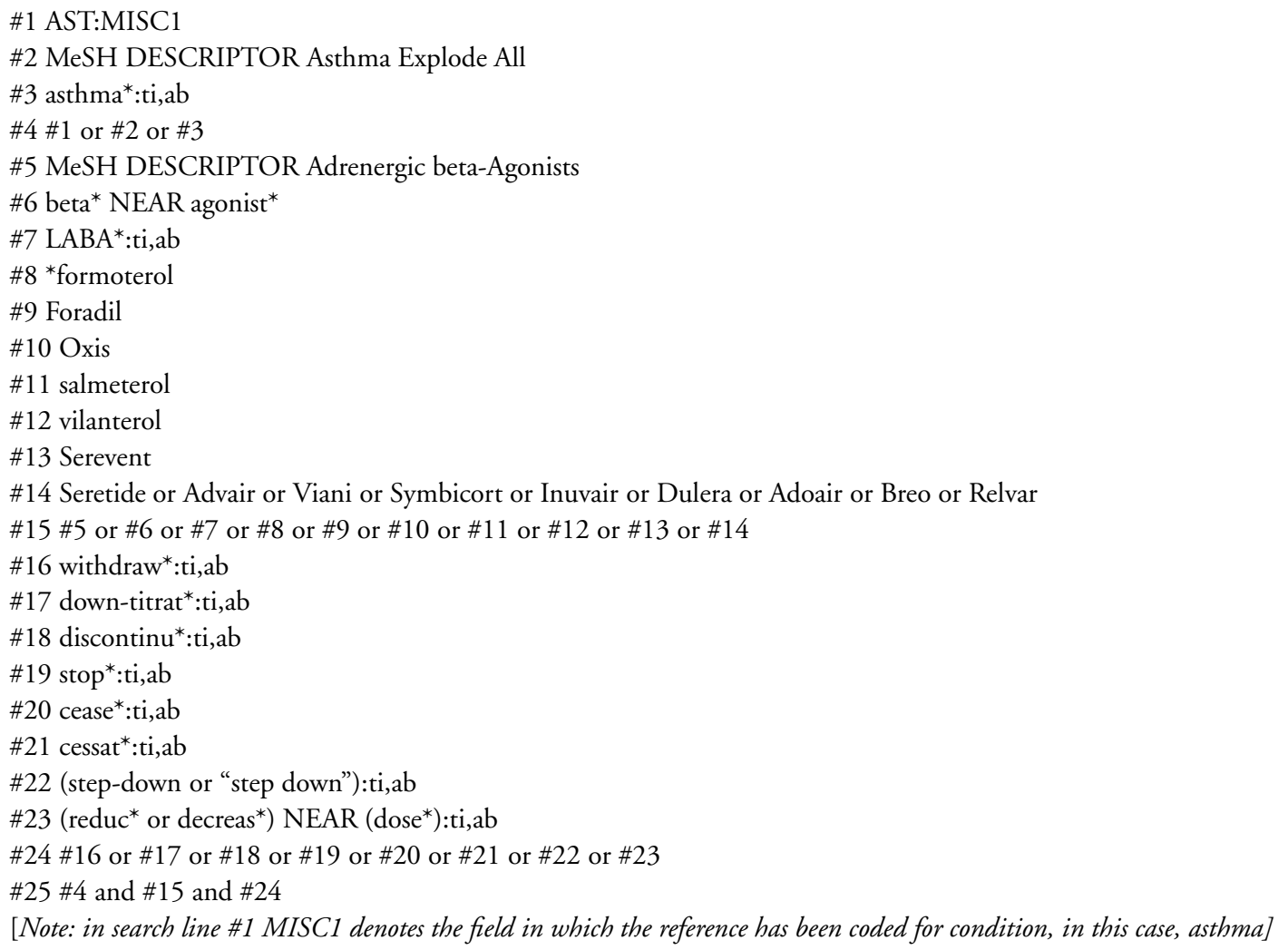

\section{CONTRIBUTIONSOFAUTHORS}

Shaleen Ahmad searched clinicaltrials.gov and drug company trial registries. Shaleen Ahmad and Kayleigh Kew sifted the main electronic search and the results from additional searching, and compiled the study shortlist. Sean Beggs and Kayleigh Kew made the final decisions on study exclusion. Kayleigh Kew wrote up the draft manuscript with clinical and editorial appraisal from Sean Beggs.

\section{DECLARATIONSOF INTEREST}

Kayleigh Kew: none known

Sean Beggs: none known

Shaleen Ahmad: none known 


\section{SOURCES OF SUPPORT}

\section{Internal sources}

- Kayleigh Kew, UK.

St George's University, London

- Shaleen Ahmad, UK.

St George's University, London

- Sean Beggs, Other.

No such funding was received for this review

\section{External sources}

- Kayleigh Kew, UK.

National Institute of Health Research: Evidence to guide care in adults and children with asthma, 13/89/14

\section{DIFFERENCESBETWEEN PROTOCOLANDREVIEW}

No trials met the inclusion criteria for this review, we were unable to conduct meta-analyses, implement any of the data analysis plan, or conduct any of the planned subgroup or sensitivity analyses. 